\title{
ALD Pt Nanoparticles and Thin-Film Coatings Enhancing the Stability and Performance of Silicon Photocathodes for Solar Water Splitting
}

\author{
Christos Trompoukis, ${ }^{* a b} \mathrm{Ji}$-Yu Feng, ${ }^{\mathrm{c}}$ Tom Bosserez, ${ }^{a}$ Jan Rongé, ${ }^{a}$ Jolien Dendooven, ${ }^{\mathrm{c}}$ Christophe Detavernier, ${ }^{\mathrm{c}}$ Roel Baets, ${ }^{\mathrm{b}}$ \\ Johan A. Martens ${ }^{a}$ \\ a. KU Leuven, COK-KAT, Celestijnenlaan 200F, Leuven, Belgium. \\ b. Ghent University, Photonics Research Group, iGent, Technologiepark Zwijnaarde 126, Ghent, Belgium. \\ c. Ghent University, Department of Solid State Sciences, Krijgslaan 281/S1, 9000 Gent, Belgium \\ * corresponding author: christos.trompoukis@kuleuven.be
}

\begin{abstract}
We report on thin-film coatings and catalyst nanoparticles both deposited by atomic layer deposition (ALD) on silicon (Si) photocathodes that simultaneously enhance their performance and stability. Regarding thin-film coatings, we scan various materials $\left(\mathrm{SiO}_{2}, \mathrm{TiO}_{2}\right.$ and $\left.\mathrm{Al}_{2} \mathrm{O}_{3}\right)$ appropriate for the electrical passivation of Si surface defects, which result in high minority carrier lifetimes (up to $100 \mu \mathrm{s}$ ). However, these passivating layers seem to act as a barrier for the photogenerated carriers obstructing them from participating in the hydrogen evolution reaction, thus limiting the onset potential $\left(\mathrm{V}_{\mathrm{on}}\right)$. Regarding platinum $(\mathrm{Pt})$ nanoparticles, two deposition approaches are followed based on using different co-reactants during the ALD process, i.e. an $\mathrm{O}_{2}$ pulse or a $\mathrm{N}_{2}$-plasma pulse, with the latter resulting in a higher $\mathrm{V}_{\text {on }}(505 \mathrm{mV}$ ). By combining thin-film $\mathrm{SiO}_{2}$ coatings of various thicknesses deposited on top of ALD Pt nanoparticles, a synergetic effect of performance and stability enhancement is observed, with $\mathrm{V}_{\text {on }}$ values reaching $525 \mathrm{mV}$. Finally, by systematically studying the Si photocathodes in a day/night cycle operation and using the case of electroless deposited Pt nanoparticles as a benchmark, the $\mathrm{N}_{2}$-plasma deposited Pt nanoparticles coated by ultra-thin $\mathrm{SiO}_{2}$ film show an enhanced stability (85h-4 days/night cycles).
\end{abstract}

\section{Introduction}

The world is going through an accelerated energy transition from fossil fuels towards renewable sources. During the last decade, the major renewable energy technologies (i.e. solar photovoltaic (PV) and wind energy) went through a significant cost reduction and as a result they have achieved an increasing penetration in the energy production landscape. However, those renewable energy technologies provide a sustainable solution in the form of electricity which covers at the moment only $20 \%$ of our energy needs. The remaining $80 \%$ is consumed in the form of fuels (oil, gas, coal and biomass). Optimistic projections predict only $40 \%$ of electrification by 2050 and limited renewable alternatives for the $60 \%$ consumed as fuels. ${ }^{1,2}$ Even if we manage to achieve near $100 \%$ electrification of our societies, enhanced grid flexibility and feedstock (e.g. to fabricate materials) will still be needed requiring not only short-term but also long-term storage. Therefore, renewable fuels are required and will be a crucial factor to enable a sustainable future. Hydrogen $\left(\mathrm{H}_{2}\right)$ in particular can substitute fossil fuels not only in end applications which are difficult to electrify (seasonal storage or heavy-duty mobility) but also in sectors which have limited renewable alternatives (industrial fuels).

Although sunlight-driven water splitting systems have been proposed already since the 1970 s, the delay of realizing a highly-efficient, low-cost and stable device has resulted in skepticism. ${ }^{3,4}$ Nevertheless, through the last decades the field of photoelectrochemical (PEC) water splitting has advanced significantly. A holistic approach has been identified as a prerequisite not only for designing PEC systems but also for developing new materials and strategies for efficient and longlasting solar water splitting devices. ${ }^{5}$ Meaningful combinations of photoanodes and photocathodes as well as state-of-the-art highly performing materials and concepts for stand-alone devices have been defined and developed. ${ }^{6}$ To that end, various device designs have been proposed focusing on semiconductor/liquid junctions, solid state junctions, metal insulator semiconductor (MIS) junctions, insulator metal insulator semiconductor (IMIS) junctions etc., aiming at achieving as high photovoltage and photocurrent as possible. ${ }^{7}$ ${ }^{9}$ At the same time, thin-film coatings have also been used for improving the surface electrical passivation and chemical protection against material corrosion aiming at enhancing the electrochemical stability of photoelectrodes in contact with aqueous electrolytes. ${ }^{10}$ However, most of the stability tests reported so far cover a period of a few hours (see review papers from J. W. Ager et al. and D. Bae et al.), with only a few studies demonstrating a continuous operation for several days (for example, X. Zhou et al. for photoanodes and C. Ros et al. for photocathodes), while the diurnal effect on the photoelectrode's performance has only recently started to be investigated. $6,11-14$

Silicon ( $\mathrm{Si}$ ) is one of the materials most frequently used as a photocathode, not only because of its compatibility with the whole semiconductor industry but also because of its relevant band-gap for solar applications. Despite the fact that $\mathrm{Si}$ is an 
indirect semiconductor and thus the optical absorption is not optimal, its band-gap is close to the optimal value for reaching the maximum efficiency limits. ${ }^{15,16}$ The operation of $\mathrm{p}$-type $\mathrm{Si}$ in acidic electrolytes comprises a stable system for illuminated periods during which a photovoltage is created. However, during night-time the Si photocathode remains in direct contact with the acidic electrolyte without the added benefit of a photovoltage providing a cathodic bias. Therefore, the formation of oxide or silicic acid $\left(\mathrm{SiO}_{2}\right.$ and $\left.\mathrm{H}_{2} \mathrm{SiO}_{3}\right)$ on the $\mathrm{Si}$ surface upon exposure to acidic electrolytes causes its deactivation. $6,17,18$ Even if the self-limiting growth of those oxides results in a slow corrosion rate of $\mathrm{Si}$, the charge transport which is needed for driving the hydrogen evolution reaction is hindered. As a result, the presence of the surface oxides eventually deactivates the photoelectrode by imposing a high resistance for electrons. Finally, the operational stability of Si photoelectrodes incorporating catalysts (an indispensable part of the photoelectrode design used to minimize the overpotentials) is of great importance for a long-lasting and highly-performing device. While platinum is a catalyst material usually employed for the hydrogen evolution reaction, the stability degradation of platinum nanoparticles on top of $\mathrm{Si}$ photocathodes poses significant restrictions. In particular, various mechanisms have been proposed such as the dissolution, oxidation, coalescence or physical detachment of the catalyst as well as a general performance degradation which is proportional to the current densities (the presence of $\mathrm{H}_{2}$ bubbles which remain attached on the surface of the photoelectrodes could force high local current densities on Pt nanoparticles located at the bubble's edge resulting in an accelerating local degradation). ${ }^{9,} 19$

In this paper, we report on ALD coatings deposited on $\mathrm{Si}$ photocathodes which can simultaneously enable high photoelectrode performance and stable operation. We first scan various thin-film coatings traditionally used by the PEC and PV fields for the electrical passivation of surface defects to improve the performance of the Si photocathodes. In particular, we study the effect of the surface passivation on the lifetimes and the PEC performance of the photocathodes. We then investigate various approaches combining $\mathrm{Pt}$ nanoparticles and protective thin-film coatings, both deposited by $A L D$, in order to enable a synergetic effect of performance and stability enhancement. Finally, we systematically study the operation of the Si photocathodes on a day/night cycle operation in order to understand how the diurnal real-life conditions affect the performance of the photocathodes.

\section{Results and discussion}

In order to achieve high PEC performances, and therefore high solar to hydrogen efficiencies, the obtained photovoltage and photocurrent should be maximized. ${ }^{8}$ Regarding the photovoltage, solid state junctions $\left(\mathrm{pn}^{+}\right)$have demonstrated higher values compared to the semiconductor/liquid junctions (bare p-type silicon photocathode vs bare pn+ silicon photocathode, results shown in Figure S1). Additionally, the presence of catalysts such as platinum $(\mathrm{Pt})$ is essential for minimizing overpotentials. Regarding the photocurrent, a trade-off between overpotentials and saturation currents should be maintained with respect to the Pt loadings. As seen in Figure S1, although higher Pt loadings result in a more positive onset potential, fewer minority carriers are generated (because of fewer photons entering the photoactive material) and thus less photocurrent is obtained. Finally, strongly acidic or alkaline electrolytes are normally employed so as to provide low Ohmic losses in the device and avoid the creation of $\mathrm{pH}$ gradients unless less conventional design approaches are used. ${ }^{20,21}$ However, several materials are unstable when operating under such conditions while their deposition method influences the robustness of the design thus resulting in device degradation. Silicon is well-known to be chemically etched in alkaline conditions while it forms an oxide in an acidic environment. As summarized in the review paper of $\mathrm{C}$. Ros et al., certain metal oxides such as $\mathrm{BiVO}_{4}$ and $\mathrm{Al}_{2} \mathrm{O}_{3}$ and some transparent conducting oxides such as $\mathrm{ZnO}_{2}$ and ITO lack stability in highly acidic or alkaline. ${ }^{7}$ Non-noble metal alloys such as $\mathrm{Ni}-\mathrm{Mo}$ have been reported to chemically corrode under acidic conditions therefore resulting in limited stability. ${ }^{10}$ Finally, depending on the technique used for the deposition of materials which are directly in contact with the electrolyte, a device can degrade faster due to pitting and eventually corrosion when the $\mathrm{pH}$ changes. ${ }^{22}$

In order to tackle the operational instability, various thinfilm coatings have been proposed for the chemical protection of the silicon surface in direct contact with an electrolyte. ${ }^{10} \mathrm{At}$ the same time, such coatings have been traditionally used in the field of solar photovoltaics in order to enable the electrical passivation of the silicon surface and achieve higher minority carrier lifetimes thus enabling higher photovoltage values. ${ }^{23,} 24$ In the following section we discuss the application of several thin-film coatings deposited by ALD for the electrical passivation and chemical protection of Si photocathodes as well as for the enhancement of the catalytic activity without compromising the achieved saturation current densities.

ALD coatings for electrical passivation Figure 1a summarizes the minority carrier lifetimes we measured for the unpassivated photocathode used as a reference as well as the photocathodes which were passivated with $\mathrm{SiO}_{2}, \mathrm{TiO}_{2}$ and $\mathrm{Al}_{2} \mathrm{O}_{3}$. The unpassivated photocathode reaches minority carrier lifetimes of $4 \pm 1 \mu \mathrm{s}$.

Aluminum oxide $\left(\mathrm{Al}_{2} \mathrm{O}_{3}\right)$ effectively passivates the $\mathrm{Si}$ surfaces thus reaching lifetimes of $87 \pm 14$ (best sample has a lifetime of $101 \mu \mathrm{s}$, a value which for this type of wafers is comparable to state-of-the-art passivation of the same type of wafers by intrinsic amorphous silicon). ${ }^{25}$ Regarding $\mathrm{TiO}_{2}$, a thinner layer results in higher lifetimes compared to a thick one as already reported in literature while for the $\mathrm{SiO}_{2}$ coating lifetimes of $9 \pm 1 \mu$ s are obtained. ${ }^{26}$ Overall, all coatings resulted in lifetime values which are higher than the value measured for the unpassivated case, with $\mathrm{Al}_{2} \mathrm{O}_{3}$ showing the best performance.

Those results are in line with existing literature showing that surface coatings (such as $\mathrm{SiO}_{2}, \mathrm{TiO}_{2}$ and $\mathrm{Al}_{2} \mathrm{O}_{3}$ ) aiming at passivating any surface defects can indeed increase the minority carrier lifetimes. ${ }^{27}$ Despite an enhanced electrical passivation, all thin-film coatings resulted in worse PEC performance compared to the unpassivated case. As shown in Figure $1 b$, the onset potential ( $\left.V_{\text {on }}\right)$ of the ALD coated photocathodes was more negative. Although the minority carrier lifetimes for the ALD coated samples were improved, their electrochemical performance on the contrary decreased, highlighting a trade-off between the two. It has been reported that the kind of precursors, the conditions during the ALD deposition, the post-deposition annealing process and the thickness of the deposited layer have an impact (positive or 


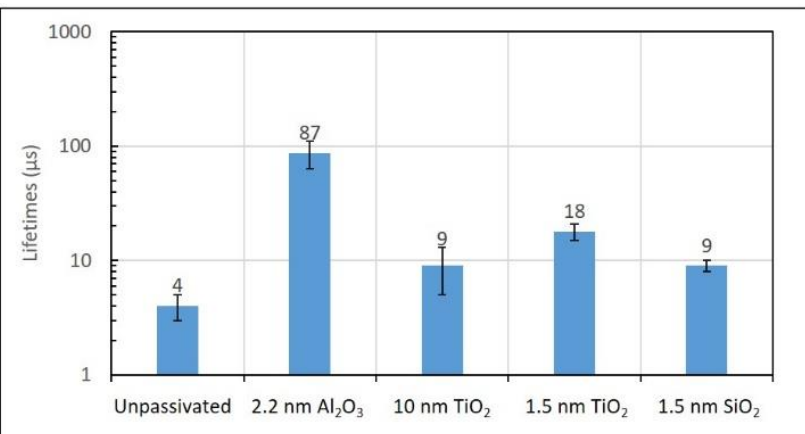

a)

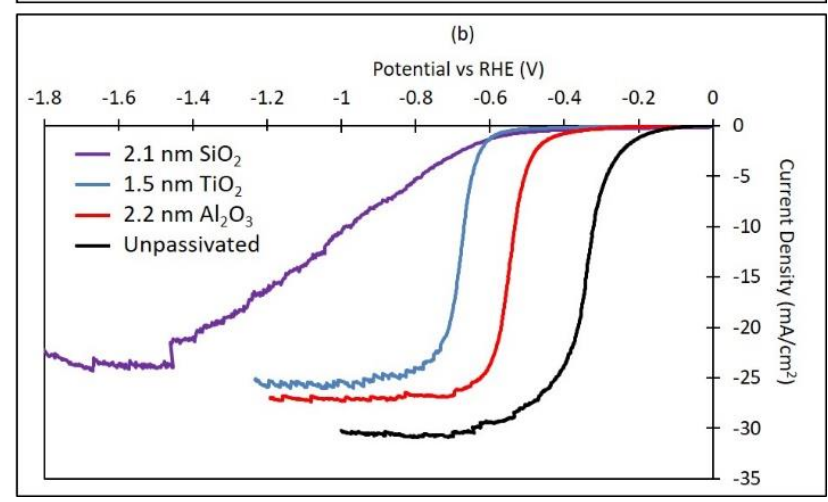

Figure 1 a) Minority carrier lifetimes of flat $p$-type silicon samples coated by various thin-films by atomic layer deposition (ALD) and b) their current density - voltage (JV) results highlighting a trade-off between lifetimes and PEC performance. $0.5 \mathrm{M}$ of sulfuric acid $\left(\mathrm{H}_{2} \mathrm{SO}_{4}\right)$ was used as the electrolyte.

negative) on the electrochemical performance of the studied photoelectrode. ${ }^{27-29}$ As for the involved transfer of charges through the deposited layers, i) tunnelling, ii) charge transfer through defects resulting in a "leaky dielectric" as well as iii) a more complex case involving their combination have been proposed as the charge transfer mechanism. ${ }^{29-30}$ For the case of $\mathrm{SiO}_{2}$, the material's bandgap acts as a barrier for charge transfer unless a very thin layer is deposited which allows tunnelling. We focused here on the thickness of $2.1 \mathrm{~nm}$ of $\mathrm{SiO}_{2}$ since this was the thickness that resulted in the most stable photoelectrode (results shown in a later section about the day/night operation of the photocathodes). A thinner $\mathrm{SiO}_{2}$ could result in a better performance but this would also mean a less stable final (i.e. with Pt nanoparticles) photoelectrode. The case of $\mathrm{TiO}_{2}$ is interesting because of the favourable band alignment to silicon. However, a negative effect was described by Seger et al. based on which the pinning of the $\mathrm{TiO}_{2}$ at the electrolyte interface keeps electrons from passing this barrier thus not contributing to the hydrogen evolution reaction. ${ }^{30}$

While an improvement was shown for $n$-type Si photoanodes after carefully optimizing the deposition conditions, $\mathrm{Z}$. Xing et al. showed that similar to our work, their $\mathrm{TiO}_{2}$ coated p-type photocathodes had a more negative onset potential compared to the bare silicon photoelectrode that they used as a reference. ${ }^{10,31}$ They attributed this negative effect to the overlap of the two space charge layers at the electrolyte/ $\mathrm{TiO}_{2}$ and $\mathrm{TiO}_{2} / \mathrm{Si}$ interfaces forming an electron trap. We should finally highlight here the case of $\mathrm{Al}_{2} \mathrm{O}_{3}$ which is amphoteric and thus unstable both in acidic and in alkaline electrolytes. Indeed, $\mathrm{Al}_{2} \mathrm{O}_{3}$ is reduced to $\mathrm{Al}^{+}$when operated at negative potentials in extreme electrolyte $\mathrm{pH}$ values as reported previously. ${ }^{18}$ In our tests, although the $\mathrm{Al}_{2} \mathrm{O}_{3}$ coated photocathodes reached the highest lifetimes, they were unstable during the $\mathrm{CV}$ scans (Figure S2) contrary to existing literature reporting on an enhanced photoelectrochemical performance of $\mathrm{Al}_{2} \mathrm{O}_{3}$ coated photocathodes. ${ }^{32}$

ALD platinum nanoparticles for catalytic activity The catalytic activity of Pt nanoparticles depends on their geometry (size and shape) as well as their surface coverage. Using the most employed ALD process for Pt deposition, based on trimethyl(methylcyclopentadienyl)platinum ( $\mathrm{MeCpPtMe}_{3}$ ) as a precursor and $\mathrm{O}_{2}$ as reactant, the catalytic activity of the $\mathrm{pn}^{+} \mathrm{Si}$ photocathode with deposited Pt nanoparticles (from now on referred to as $\mathrm{pn}^{+} \mathrm{Si} \_\mathrm{Pt}-\mathrm{O}_{2}$ ) was improved compared to the bare $\mathrm{pn}^{+} \mathrm{Si}$ case. ${ }^{33}$ As shown in Figure 2, there was a positive shift in the $\mathrm{V}_{\text {on }}$ of $245 \mathrm{mV}$ (from 100 to $345 \mathrm{mV}$ ) thanks to the presence of the Pt nanoparticles. As mentioned in the experimental section, we consider $V_{\text {on }}$ to be the point at which the current density is 0.1 $\mathrm{mA} / \mathrm{cm}^{2}$ so that we could compare data in a consistent way. However, the kinetics were hindered and as a consequence the fill factor (FF) was affected thus resulting in a worse overall photoelectrochemical performance. As will be discussed later in the manuscript, such a behaviour can be explained by the presence of an oxide layer grown in between the Pt nanoparticles and the $\mathrm{pn}^{+} \mathrm{Si}$ photocathode during the $\mathrm{O}_{2}$ pulse step.

An alternative process for the deposition of Pt nanoparticles by ALD was reported by Longrie et al. and used $\mathrm{N}_{2}$ plasma as the reactant, thus avoiding the use of $\mathrm{O}_{2} \cdot{ }^{34}$ Such an approach was also used by Dendooven et al. for the independent control of Pt particle size and coverage..$^{35}$ The photoelectrochemical performance of the $\mathrm{pn}^{+} \mathrm{Si}$ photocathodes coated with Pt using the $\mathrm{N}_{2}$-based plasma process (from now on referred to as pn+Si_Pt- $\mathrm{N}_{2}$ ) was significantly enhanced when compared to both the bare $\mathrm{pn}^{+} \mathrm{Si}$ and the pn+Si_Pt$\mathrm{O}_{2}$ samples. First, the $\mathrm{V}_{\text {on }}$ reached a value up to $505 \mathrm{mV}$ because of an enhanced catalytic activity. Second, the saturation current was similar to the bare $\mathrm{pn}^{+} \mathrm{Si}$ case highlighting the limited amount of light which was blocked by the presence of the nanoparticles.

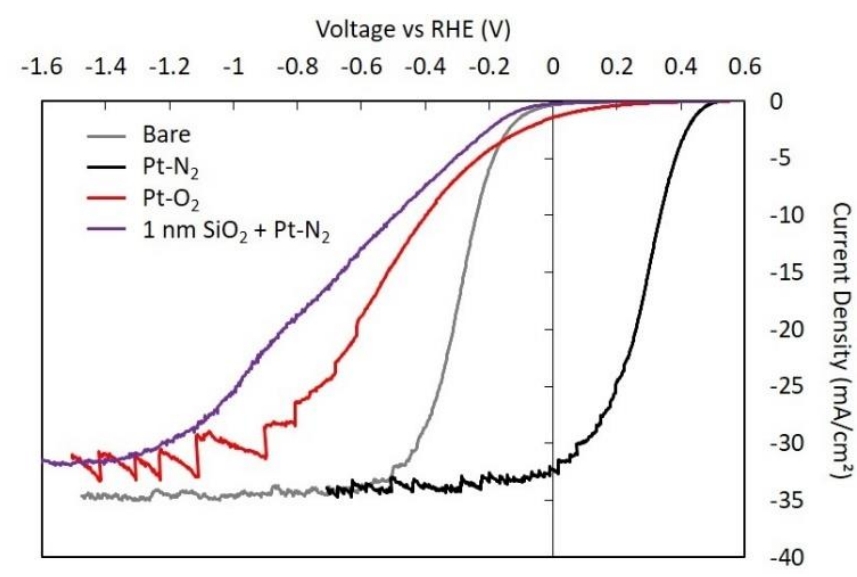

Figure 2. Current density - voltage (JV) results for the random pyramid textured bare $\mathrm{pn}^{+} \mathrm{Si}$ photocathode (grey), the ALD Pt nanoparticle decorated $\mathrm{pn}^{+} \mathrm{Si}$ photocathodes using the $\mathrm{N}_{2}$-plasma (black) and the $\mathrm{O}_{2}$-pulse (red) process as well as the case of the 1 $\mathrm{nm}$ thin $\mathrm{SiO}_{2} .0 .5 \mathrm{M}$ of sulfuric acid $\left(\mathrm{H}_{2} \mathrm{SO}_{4}\right)$ was used as the electrolyte. 
Additionally, the fill factor remained unaffected indicating fast kinetics and low resistive losses for the electrons to participate to the evolution reactions. Such a behaviour contrasts with the case when the $\mathrm{O}_{2}$ pulse was used during the ALD process.

In order to further investigate the hypothesis that, contrary to the process using the $\mathrm{N}_{2}$ plasma, an insulating oxide is forming between the $\mathrm{Si}$ photocathode and the $\mathrm{Pt}$ nanoparticles during the process using the $\mathrm{O}_{2}$ pulse, we deposited a thin $(1 \mathrm{~nm}) \mathrm{SiO}_{2}$ coating by ALD before the $\mathrm{N}_{2}$ plasma-based Pt nanoparticle deposition. As shown in Figure 2, the photoelectrode having a $1 \mathrm{~nm}$ thin $\mathrm{SiO}_{2}$ coating between $\mathrm{Si}$ and the Pt nanoparticles has performance characteristics resembling the photoelectrode undergoing the $\mathrm{Pt}-\mathrm{O}_{2}$ process.

It should be mentioned here that although Pt is an expensive and noble material to be widely used as a catalyst for the HER, low loadings could enable TW scale PEC applications. ${ }^{36}$ The elemental composition of materials on the samples we have measured via XRF corresponds to a Pt loading of $2.85 \mu \mathrm{gr} / \mathrm{cm}^{2}$. Thanks to the tunability and the precise control on loadings the ALD deposition process offers, reducing the $\mathrm{Pt}$ loading by an order of magnitude is possible so as to be on the right track. ${ }^{35}$ Although this would compromise the photovoltage since a higher overpotential will be required, the resulting PEC performance could still be acceptable compared to non-noble catalysts.

ALD coatings for stability enhancement Unprotected silicon surfaces will eventually become inactive either i) when in contact with a liquid electrolyte during the dark periods where there is no illumination and therefore no photovoltage or ii) due to the performance degradation during storage (aging). ${ }^{37}$ For the first case, bare $\mathrm{pn}^{+} \mathrm{Si}$ photocathodes result in worse $\mathrm{PEC}$ behaviour after remaining in contact with $0.5 \mathrm{M} \mathrm{H}_{2} \mathrm{SO}_{4}(\mathrm{pH}=0.4)$ overnight. They only restore their initial properties when the $\mathrm{SiO}_{2}$ which grew overnight is reduced. Regarding aging, the native oxide which grows on the silicon surface during storage of the photocathodes in ambient air has a similar effect. ${ }^{37}$ Overcoating the photocathodes with protective layers after the Pt catalyst deposition would not only avoid their vulnerability to aging but it would also secure their operating stability by avoiding the growth of the insulating oxide during dark periods and the agglomeration of Pt nanoparticles during operation. ${ }^{19}$

Following a similar approach to D. Esposito's work, we coated the ALD Pt-decorated photocathodes (only the ones following the $\mathrm{N}_{2}$-plasma process since they showed the most promising performance) with an $\mathrm{ALD} \mathrm{SiO}_{2}$ capping layer of various thicknesses. ${ }^{19}$ Variation of the thickness was achieved by varying the number of ALD cycles applied, i.e. 10, 20, 30, 50 and 70 cycles of $\mathrm{SiO}_{2} \mathrm{ALD}$. The steady growth per cycle for this process was found to be $\sim 0.07 \mathrm{~nm} /$ cycle based on in situ spectroscopic ellipsometry measurements during ALD on a planar Si reference wafer. In the following, the various samples are labelled according to the thickness of their $\mathrm{SiO}_{2}$ capping layer, obtained by multiplying the number of ALD cycles with the mentioned growth per cycle, yielding values of $0.7 \mathrm{~nm}, 1.5 \mathrm{~nm}, 2.1 \mathrm{~nm}, 3.5 \mathrm{~nm}$ and $5.0 \mathrm{~nm}$, respectively. Note that we have implicitly assumed that the growth per cycle on the Pt nanoparticles does not deviate from the steady growth per cycle, however, the deposited amount of $\mathrm{SiO}_{2}$ per ALD cycle may deviate during the initial ALD cycles on Pt due to nucleation effects. ${ }^{38,} 39$ Hence, the indicated film thicknesses should be regarded as estimates and not as precise values of the actual thicknesses, especially for the samples which received only a few ALD cycles. Further characterization (e.g. TEM) would give a more precise picture of the exact thickness of the ALD coatings on the Pt nanoparticles.

As shown in Figure 3, there is a trade-off between the thickness of the $\mathrm{SiO}_{2}$ capping layer and the $\mathrm{PEC}$ performance of the photocathodes. In particular, the thicker the $\mathrm{SiO}_{2}$ the worse the $\mathrm{V}_{\text {on }}$ and FF. For the thicknesses of 0.7 and $1.5 \mathrm{~nm}$, a high $\mathrm{V}_{\text {on }}(\sim 525 \mathrm{mV})$

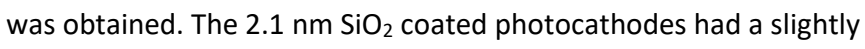
lower $\mathrm{V}_{\text {on }}\left(485 \mathrm{mV}\right.$ ) and $\mathrm{FF}$, while for thicker $(3.5 \mathrm{~nm}$ and $5 \mathrm{~nm}) \mathrm{SiO}_{2}$ coating both the $\mathrm{V}_{\text {on }}$ and the FF were severely compromised.

Compared to the reference case which we used for benchmarking $\left(\mathrm{pn}^{+} \mathrm{Si}\right.$ with Pt nanoparticles which were deposited by electroless deposition), the best performing photoelectrodes coated by ALD showed a similar $V_{\text {on }}$ of $\sim 525 \mathrm{mV}$, with higher photocurrents ( 33 $\mathrm{mA} / \mathrm{cm}^{2}$ ) and lower FF. Table S1 contains a summary of all the relevant parameters ( $\mathrm{J}_{\mathrm{sc}}, \mathrm{V}_{\mathrm{on}}$ and $\mathrm{FF}$ ) for a better comparison of the results shown in Figure 3.

As shown in the SEM pictures of the as-deposited Pt catalysts in Figure 4 and 5, the Pt nanoparticles which result from the electroless deposition have an average diameter of around $35 \pm 8$ $\mathrm{nm}$, while the ALD Pt nanoparticles have a smaller diameter around $5 \pm 1 \mathrm{~nm}$. This could result in more parasitic (i.e. elsewhere than the photoactive material, here in the Pt nanoparticles) absorption in the former and therefore less light entering the photoelectrode resulting in a lower photocurrent. Regarding FF, since the $\mathrm{SiO}_{2}$ coating is an insulating layer, it obstructs the evolution reactions. A limited number of $\mathrm{SiO}_{2}$ ALD cycles is expected to result in a noncontinuous film on the Pt nanoparticles, yielding patches of coating, potentially preferentially on low-coordination $\mathrm{Pt}$ sites, with uncoated areas in between (see schematics in Figure S5e). ${ }^{40} \mathrm{~A}$ thicker $\mathrm{SiO}_{2}$ film would further cover the Pt nanoparticles, but a

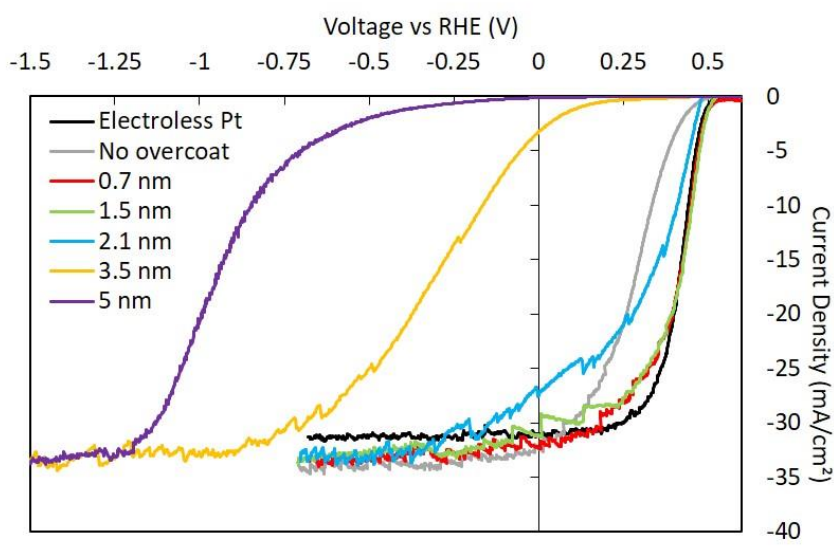

Figure 3. Current density - voltage (JV) results of ALD Pt- $\mathrm{N}_{2}$ nanoparticle decorated random pyramid textured $\mathrm{pn}+\mathrm{Si}$ photocathodes coated by $\mathrm{ALD} \mathrm{SiO}_{2}$ films of various thicknesses and benchmarking of their performance with respect to the reference case ( $\mathrm{pn}^{+} \mathrm{Si}$ with Pt nanoparticles deposited by electroless deposition). $0.5 \mathrm{M}$ of sulfuric acid $\left(\mathrm{H}_{2} \mathrm{SO}_{4}\right)$ was used as the electrolyte. 
continuous $\mathrm{SiO}_{2}$ coating would form a barrier for the electrons to contribute to the hydrogen evolution reaction. As a result, the kinetics are hindered and the overpotentials to sustain a specific current density are increased. Regarding $\mathrm{V}_{\text {on }}$, as mentioned earlier, the catalytic activity of the ALD coated photoelectrodes was similar to the reference electroless deposition with the added value of a better control on the Pt nanoparticle size.

It should be mentioned here that the difference seen in the photoelectrochemical performance of the pn ${ }^{+} \mathrm{Si}_{-} \mathrm{Pt}-\mathrm{N}_{2}$ photocathodes with and without the ALD $\mathrm{SiO}_{2}$ overcoats are probably due to the modification of the $\mathrm{Pt}$ nanoparticles during the $\mathrm{SiO}_{2}$ deposition and more specifically due to the $\mathrm{O}_{2}$ plasma. To further investigate the role of the $\mathrm{O}_{2}$ plasma pulse, we applied an $\mathrm{O}_{2}$ plasma treatment without breaking the vacuum after the $\mathrm{Pt}-\mathrm{N}_{2}$ nanoparticles were deposited. As shown in Figure $\mathrm{S} 3$, the presence of $\mathrm{O}_{2}$ plasma has a beneficial effect on the performance of the photocathode. Further tests should be performed to clarify the exact mechanism. To date, in situ grazing incidence small angle $X$ ray scattering studies confirmed that $\mathrm{Pt}$ nanoparticle ripening can occur upon exposure to $\mathrm{O}_{2}$ plasma (data not shown here).

Day/night operation So far, the performance of the photocathodes was evaluated based on their current density-voltage characteristics. However, in real-life conditions the photoelectrodes would operate in a day-night cycle. During such an operation there are two elements to take into account. On one hand, the stability of the photocathode should be high for a continuous and efficient hydrogen evolution reaction during the illuminated periods. On the other hand, the photocathode should not be affected by the direct contact to the electrolyte during dark periods without the protection from the cathodic photovoltage. We performed chronoamperometry (CA) measurements based on a 15-hour illuminated period during which the photoelectrode was operating under 1-sun illumination at $0 \mathrm{~V}$ vs RHE and a 9-hour dark period during which the photoelectrode was in open circuit. Cyclic voltammetry measurements were done before and after the $C A$ measurement. For those tests, we focused on the Pt nanoparticles deposited by the $\mathrm{N}_{2}$-plasma ALD process capped with a $\mathrm{SiO}_{2} \mathrm{ALD}$ coating of $0.7 \mathrm{~nm}$ and $2.1 \mathrm{~nm}$, respectively, and we used the photocathode with the electroless deposited Pt as the benchmark case.

In Figure 4, the case of the $\mathrm{pn}^{+} \mathrm{Si}$ photocathode coated with Pt nanoparticles via electroless deposition is shown. The SEM picture of the as-deposited sample before the experiment shows a nanoparticle size of around $35 \pm 8 \mathrm{~nm}$. The numbers depicted in the CA graph in Figure $4 \mathrm{c}$ indicate the timing at which the CV curves in Figure $4 \mathrm{~d}$ are recorded, and correspond in colour with the respective $\mathrm{CV}$ curves. As can be seen from the $\mathrm{CA}$ measurement (Figure 4c), the current density is significantly reduced within a few hours of operation. During the first 15 hours, the photocathode's JV characteristics changed from the black to the red curve shown in Figure 4d. As confirmed by SEM inspection of the sample after the full CA measurement, the Pt nanoparticles agglomerated during
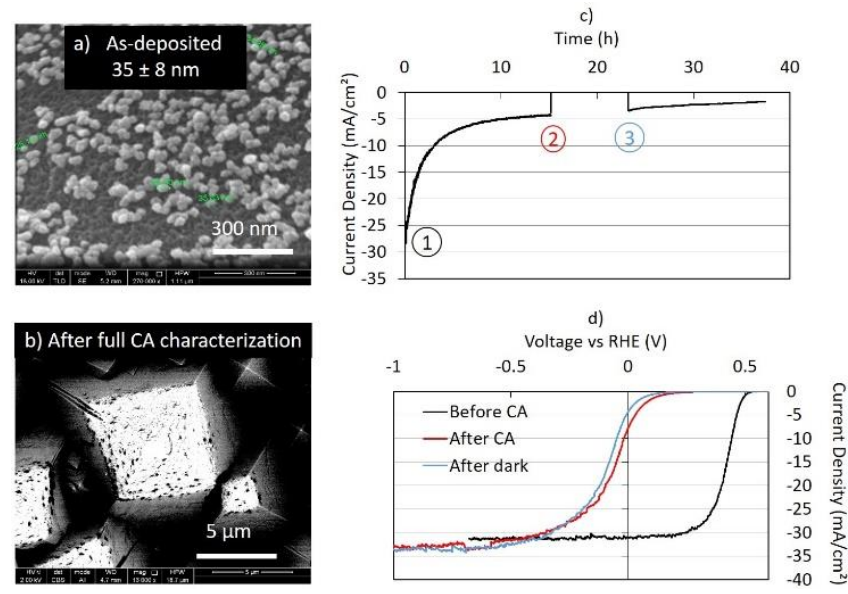

Figure 4. Day/night operation for random pyramid textured $\mathrm{pn}^{+} \mathrm{Si}$ photocathodes coated with Pt nanoparticles deposited by electroless depositions: SEM images for a) the as-deposited nanoparticles and b) after the full chronoamperometry test, c) chronoamperometry results (current density vs time) for 15 hours of illumination followed by 9 hours of dark period and d) current density - voltage (JV) curves before (black, timing 1 in (c)) and after (red, timing 2 in (c)) the CA as well as after the dark period (blue, timing 3 in (c)). $0.5 \mathrm{M}$ of sulfuric acid $\left(\mathrm{H}_{2} \mathrm{SO}_{4}\right)$ was used as the electrolyte.

operation, gathering on the tip of the pyramid. As a result, the $V_{\text {on }}$ was reduced by several hundreds of millivolts.

The case of the pn+Si_Pt- $\mathrm{N}_{2}$ photocathodes coated with two different $\mathrm{SiO}_{2}$ thicknesses is shown in Figure 5 and 6 . For the thinner $(0.7 \mathrm{~nm}) \mathrm{SiO}_{2}$ coating, a reduction in the current density is seen, although not as severe as for the electroless deposited Pt (Figure 5). The JV curves before and after the first 15-hour illumination period show a general decrease of the overall performance of the photocathode. The SEM image taken after the full CA characterization confirms the occurrence of Pt nanoparticle diffusion leading to some agglomeration on the tip of the pyramids. This behavior points towards a discontinuous $\mathrm{SiO}_{2}$ ALD coating
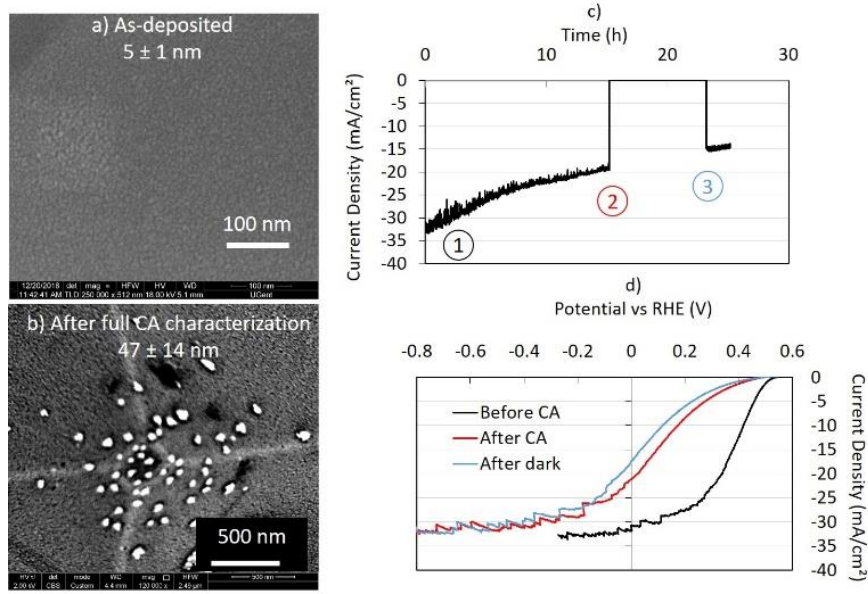

Figure 5. Day/night operation for random pyramid textured pn+Si photocathodes coated by ALD Pt nanoparticles and $0.7 \mathrm{~nm} \mathrm{SiO}_{2}$ coating deposited by ALD: SEM images for the a) as-deposited nanoparticles coated by $0.7 \mathrm{~nm} \mathrm{SiO}{ }_{2}$ and b) after the full chronoamperometry test, $\mathrm{c}$ ) chronoamperometry results (current density vs time) for 15 hours of illumination followed by 9 hours of dark period and d) cyclic voltammetry before (black, timing 1 in (c)) and after (red, timing 2 in (c)) the CA as well as after the dark period (blue, timing 3 in (c)). $0.5 \mathrm{M}$ of sulfuric acid $\left(\mathrm{H}_{2} \mathrm{SO}_{4}\right)$ was used as the electrolyte. 
allowing for the Pt nanoparticles to move and as a result the photocathode's catalytic performance degrades over time, though with a slower rate than for the uncoated photocathode. It should be noted here that the SEM magnification is different among Figures 4- 6 because of the size difference between i) the ALD-grown $\mathrm{Pt}$ and the electroless deposited Pt and ii) the Pt nanoparticles and the surface features on the Si surface (random pyramid texture is orders of magnitude larger than the Pt nanoparticles).

The stability of the photocathode is improved when a $\mathrm{SiO}_{2}$ film of $2.1 \mathrm{~nm}$ is deposited (Figure 6). Interestingly, during the first hours of operation under illumination, the current density increases, as can be seen in the CA graph in Figure $6 \mathrm{c}$. This correlates to the improvement of the FF shown in Figure $6 \mathrm{~d}$ (from the black to the red curve). This increase of the photoelectrode's performance during the first minutes/hours of operation has been observed on 5 different samples containing such a combination of ALD coatings ( $2.1 \mathrm{~nm} \mathrm{SiO}$ and Pt nanoparticles) but further tests are needed to evaluate the exact involved mechanisms. While the current density after the dark period (blue curve of Figure $6 \mathrm{~d}$ ) seems to be higher compared to the current density after the CA (red curve of Figure 6d), such a difference could be the result of the noisy profiles of $\mathrm{CV}$ scans. The increasing appearance and evolution (in size and number) of the $\mathrm{H}_{2}$ gas bubbles on the surface of the photoelectrode for current densities higher than $10-15 \mathrm{~mA} / \mathrm{cm}^{2}$ result in a noisy curve due to light-bubble interactions. As mentioned in the experimental details, the use of a surfactant was avoided in order to eliminate the relaxation of organic polymers on the photoelectrodes during the dark periods. Although the electrolyte was stirred in order to remove the $\mathrm{H}_{2}$ gas bubbles from the surface of the photoelectrode, it is often the case that some bubbles remain on the sample (and mostly at the point where the active surface area ends and the Teflon holder including a gasket start, see Figure S5 where the cell we used for the 3-electrode measurements is shown). During the operation of the
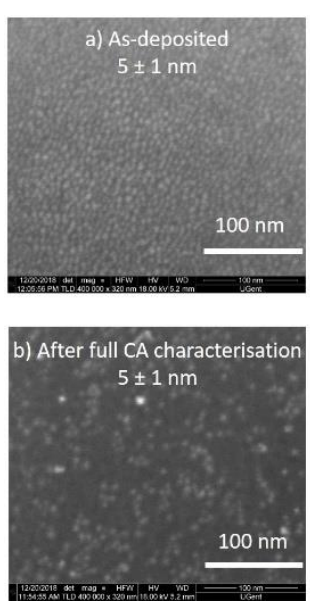

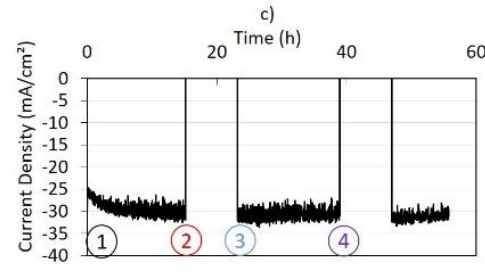

d) Voltage vs RHE (V)
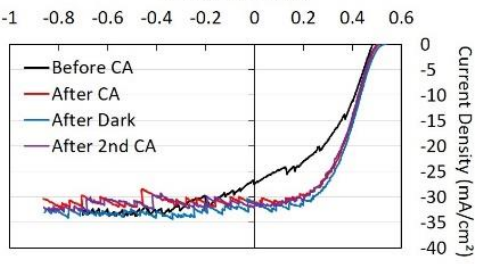

Figure 6. Day/night operation for random pyramid textured $\mathrm{pn}^{+} \mathrm{Si}$ photocathodes coated by ALD Pt nanoparticles and $2.1 \mathrm{~nm} \mathrm{SiO}{ }_{2}$ coating deposited by ALD: SEM images for a) as-deposited nanoparticles coated by $2.1 \mathrm{~nm} \mathrm{SiO}_{2}$ and b) after the full chronoamperometry test, c) chronoamperometry results (current density vs time) for 15 hours of illumination followed by 9 hours of dark period and d) cyclic voltammetry before (black, timing 1 in (c)) and after (red and purple, timings 2 and 4 in (c), respectively) the $\mathrm{CA}$ as well as after the dark period (blue, timing 3 in (c)). $0.5 \mathrm{M}$ of sulfuric acid $\left(\mathrm{H}_{2} \mathrm{SO}_{4}\right)$ was used as the electrolyte. photoelectrode at higher current densities which are measured during the $C A$, we see changes in the current density of up to 3 $\mathrm{mA} / \mathrm{cm}^{2}$ when a bubble is detached. We therefore appoint differences in current densities on the order of $<1 \mathrm{~mA} / \mathrm{cm}^{2}$ to the noisy nature of this kind of measurements and thus consider it a side-effect, especially during a CV which has a limited duration compared to the many hours of operation during the light cycle of the CA

From the SEM image it seems that although the size of the Pt nanoparticles was similar before and after the full CA characterization, some Pt nanoparticles were still able to move, probably because the $\mathrm{SiO}_{2}$ overcoat was not entirely continuous. Potentially the reorganization of the Pt occurs during the initial phase, and leads to a stabilization in the performance when only the "pinned" Pt nanoparticles remain on the photoelectrode's surface. A stable current density was measured for several day/night cycles (Figure S4). Contrary to a continuous operation for 15-hours at 1-sun illumination which is the case for the lab tests presented here, an operation at real-life conditions (i.e. lower sun intensities as well as dynamic conditions/clouds) would mean that the performance of the photocathodes could remain stable for further timescales since lower current densities would be involved. Additionally, the cathodic bias which protects the photocathodes during operation would still be present for changes in the illumination intensity (e.g. clouds). However, dedicated tests involving the cycling of the photocathodes through stepwise increase/decrease of the illumination intensity would give further information on any potential issues with stability.

Regarding the agglomeration and physical detachment of $\mathrm{Pt}$ nanoparticles, previous studies have focused on clarifying such mechanisms. ${ }^{19}$ The various proposed mechanisms regarding the stability and dynamics of the Pt nanoparticle's behavior during operating conditions indicates that pinpointing the exact mechanism can be a challenging task. Given the surface topography of our photocathodes (random pyramid textured silicon wafers) and more specifically the crystallographic orientation of the pyramid's sides (111 planes which result after anisotropic etching, i.e. crystallographic dependent etching of silicon during which there is a significant difference between the etch rates of 100 and 111 planes) preferential redeposition within a specific crystallographic plane can be excluded since the Si surface consists mainly of the same crystallographic plane. The generated $\mathrm{H}_{2}$ gas bubbles could be dragging along physically detached $\mathrm{Pt}$ nanoparticles resulting in their agglomeration at the tips of the pyramids. On the contrary, the presence of the ALD $\mathrm{SiO}_{2}$ coating on the photoelectrode's surface on one hand ensures that most of the nanoparticles remain at a fixed position and on the other hand could further prevent any redeposition of Pt nanoparticles on surface sites such as the tips of the pyramids due to a weak adhesion of nanoparticles on oxides. ${ }^{41}$ This could be more pronounced for the sample with a thicker $\mathrm{SiO}_{2}$ coating (Figure 6) for which, although we see some detachment of Pt nanoparticles, we do not have any indication of a redeposition. Further research would clarify the exact mechanism of Pt agglomeration on the tips of the pyramids. 
We could position our results based on existing review papers gathering information on the stability and performance of silicon photocathodes. Based on the review paper from D. Bae et al., the stability of our best photocathode is placed on the top-five of reported stabilities for silicon photocathodes. ${ }^{6}$ Regarding photovoltages, the quality of wafers as well as the type of junction plays a role on the $\mathrm{V}_{\text {on }}$ that can be achieved. Based on the review paper from Hu et al. where we see that most of the reported $\mathrm{pn}^{+}$ photocathodes have $\mathrm{V}_{\text {on }}$ values around $300 \mathrm{mV}$, the $\mathrm{V}_{\text {on }}$ of our best photocathode $(525 \mathrm{mV})$ is the highest. ${ }^{10}$ However, a more recent paper reports $\mathrm{V}_{\text {on }}$ values of $640 \mathrm{mV}$ which is the highest so far, to the best of our knowledge, highlighting that there is still room for improvement. ${ }^{14}$ Regarding photocurrents, the thickness of the wafers and the light trapping elements (texturing, anti-reflective coatings, metallic back reflector etc) plays a great role on the $J_{s c}$ values that can be obtained. The $\mathrm{J}_{\mathrm{sc}}$ values of our samples (around 33-34 $\mathrm{mA} / \mathrm{cm}^{2}$ ) are well in accordance with theoretical simulations for such a well-established light trapping scheme used on the surface of the silicon wafers and as a result they are among the highest reported for such wafers. ${ }^{6,10}$

\section{Conclusions}

We report on the improved performance and stability of $\mathrm{pn}^{+} \mathrm{Si}$ photocathodes when coated with $\mathrm{Pt}$ nanoparticles and $\mathrm{SiO}_{2}$ films, both deposited by ALD. The Pt nanoparticles were deposited on $\mathrm{pn}^{+} \mathrm{Si}$ photocathodes following two approaches: alternating exposures to the $\mathrm{MeCpPtMe}_{3}$ precursor and either $\mathrm{N}_{2}$ plasma (Pt$\mathrm{N}_{2}$ ) or $\mathrm{O}_{2}$ pulse $\left(\mathrm{Pt}-\mathrm{O}_{2}\right)$. The Pt- $\mathrm{N}_{2}$ had a better $\mathrm{V}_{\text {on }}$ and when capped with a $\mathrm{SiO}_{2}$ thin-film the $\mathrm{V}_{\text {on }}$ reached $525 \mathrm{mV}$, a value which is comparable to the state-of-the-art photoelectrodes reported in literature. The $\mathrm{SiO}_{2}$ on top and around the Pt nanoparticles acted as a protective capping layer against agglomeration. Compared to the reference case used for benchmarking $\left(\mathrm{pn}^{+} \mathrm{Si}\right.$ photocathodes with $\mathrm{Pt}$ nanoparticles deposited by electroless deposition) for which the catalytic activity rapidly degraded after a few hours because of the agglomeration of the nanoparticles, protecting the Pt nanoparticles by a thin $\mathrm{SiO}_{2}$ layer resulted in a more stable operation.

The results of this work could give certain guidelines for enabling a photocathode design with an efficient and stable operation. Regarding the passivating layer, while a thin coating can increase the minority carrier lifetimes, it generally deteriorates the photoelectrochemical performance of the bare semiconductor. When a Pt catalyst is carefully applied, however, this latter effect is not a dominating factor in the performance of the Pt supported photocathode. To this end, a Pt deposition process which avoids the growth of a thin interfacial oxide between the photoactive material and the catalyst is mandatory. As for the capping oxide on top of the Pt catalyst, the trade-off between stability and photoelectrochemical performance should be taken into account: a too thin oxide is not sufficient to avoid Pt agglomeration while a too thick oxide coating leads to a significantly worse photoelectrochemical behavior. Overall, such a combination of controlled Pt nanoparticle deposition and a carefully optimized protective thin-film capping layer resulting in high $\mathrm{V}_{\text {on }}$ and stable operation can enable low cost and efficient solar water splitting devices.

\section{Experimental details}

Photocathode materials Silicon (Si) p-type (1-3 $\left.\Omega \cdot \mathrm{cm}^{-3}\right)$ wafers with a thickness of approximately $160 \mu \mathrm{m}$ were used. The front surface was textured with random pyramids and the rear was planar. Moreover, the random pyramid textured side was $\mathrm{n}^{+}$-doped with phosphorus via a diffusion process resulting in an emitter sheet resistance of $85 \pm 2 \Omega / \square$. For the specific case of the lifetime tests, both surfaces were planar and there was no emitter present in order to decouple parasitic effects such as surface topography and Auger recombination from highly doped regions.

Atomic layer deposition (ALD) Atomic layer depositions were performed in a homebuilt reactor in a pumping mode. ${ }^{42}$ The native oxide was removed by an $\mathrm{HF}$ dip before the depositions. $\mathrm{Pt}$ nanoparticles were deposited at $300^{\circ} \mathrm{C}$ by alternating exposures to the $\mathrm{MeCpPtMe}_{3}$ precursor (15 s, 1 mbar) and $\mathrm{N}_{2}$ plasma (10 s, 5 $\cdot 10^{-3} \mathrm{mbar}$ ) or $\mathrm{O}_{2}$ gas $(15 \mathrm{~s}, \sim 1 \mathrm{mbar}){ }^{33-35}$ Silicon oxide $\left(\mathrm{SiO}_{2}\right)$ was coated at $300^{\circ} \mathrm{C}$ by alternating exposures to bis(diethylamino)silane (BDEAS) $\left(5 \mathrm{~s}, 1 \cdot 10^{-3} \mathrm{mbar}\right)$ and $\mathrm{O}_{2}$ plasma $\left(5 \mathrm{~s}, 5 \cdot 10^{-3} \mathrm{mbar}\right)$.

Aluminum oxide $\left(\mathrm{Al}_{2} \mathrm{O}_{3}\right)$ and titanium oxide $\left(\mathrm{TiO}_{2}\right)$ were deposited at $150^{\circ} \mathrm{C}$ by alternating exposures to trimethylaluminium (TMA) or tetrakis(dimethylamido)titanium (TDMAT) $\left(5 \mathrm{~s}, 5 \cdot 10^{-3} \mathrm{mbar}\right.$ ), respectively, and de-ionized water $\left(5 \mathrm{~s}, 5 \cdot 10^{-3} \mathrm{mbar}\right) .^{43-45}$ Between the precursor and reactant pulse, the reactor was pumped down to a base pressure of $1 \cdot 10^{-6}$ mbar. After $\mathrm{Al}_{2} \mathrm{O}_{3}$ and $\mathrm{TiO}_{2}$ coating, the samples were annealed at $350{ }^{\circ} \mathrm{C}$ in $5 \% \mathrm{H}_{2} / \mathrm{He}$ atmosphere for 30 minutes. All oxide ALD processes were characterized with in situ spectroscopic ellipsometry (J.A.Woollam) to determine the linear growth behavior on planar silicon wafers. From the linear growth curve, the growth per cycle in the steady growth regime was determined (i.e. $0.06 \mathrm{~nm}$ per cycle for $\mathrm{Al}_{2} \mathrm{O}_{3}, 0.07 \mathrm{~nm}$ per cycle for $\mathrm{SiO}_{2}, 0.07 \mathrm{~nm}$ per cycle for $\mathrm{TiO}_{2}$ ). The thicknesses of the thin-film coatings used in this work have been derived by multiplying the measured thickness per cycle with the number of applied ALD cycles. For the electroless Pt nanoparticle depositions which were used as the reference case for benchmarking the performance of the ALD-coated photocathodes, a $1 \mathrm{mM}$ Potassium hexachloroplatinate $\left(\mathrm{K}_{2} \mathrm{Cl}_{6} \mathrm{Pt}\right)$ in a $0.5 \mathrm{M} \mathrm{HF}$ solution was used.

Lifetime characterisation measurements for the quantification of minority carrier lifetimes were done using a microwave photoconductance tool on symmetric samples, i.e. similar surface finish with the passivating coating deposited on both front and rear sides of the wafer.

Photoelectrochemical characterisation Photoelectrochemical tests were performed via three-electrode measurements using an inhouse designed cell (see Figure $\mathrm{S} 5$ in the supporting information). $0.5 \mathrm{M}$ of sulfuric acid $\left(\mathrm{H}_{2} \mathrm{SO}_{4}\right)$ was used as the electrolyte. The silicon photocathodes were used as the working electrode with a surface area of $12.56 \mathrm{~mm}^{2}$ exposed to the electrolyte. The ohmic contact on the rear side of the Si photocathode was made by 
applying indium gallium eutectic paste after removing the native oxide with a diamond scribe. Graphite and $\mathrm{Ag} / \mathrm{AgCl}$ electrodes were used as the counter and the reference electrode, respectively. The three electrodes were placed in different compartments, with the reference electrode connected via a Luggin capillary tube and the counter electrode separated by a glass frit and a Nafion membrane. The use of a surfactant was avoided in order to eliminate the relaxation of organic polymers on the photoelectrodes during the dark periods which were part of the long-lasting measurements carried out for the day/night cycle operation. A continuous flow of $\mathrm{H}_{2}$ was supplied, keeping the electrolyte saturated during the illuminated periods. A potentiostat from VersaSTAT (Princeton applied research) was used for the cyclic-voltammetry (CV) and chronoamperometry (CA) measurements. The CV scans to define the current density - voltage (JV) characteristics of the photocathodes were performed using a scan rate of $10 \mathrm{mV} \mathrm{sec}-1$ from positive to negative potentials. For consistently defining the onset potential $\left(\mathrm{V}_{\text {on }}\right)$ we considered the potential at which the current density is $0.1 \mathrm{~mA} \mathrm{~cm}^{-2}$. The CA measurements were done at $0 \mathrm{~V}$ vs RHE for an illuminated period of 15 hours followed by a 9hour dark period in open circuit conditions. For the characterization of the bare silicon photocathodes, an HF dip was done right before loading the sample for removing the native oxide. A 300 W Newport Oriel lamp was used, with a water-based IR and an AM1.5 filter, calibrated for one sun illumination by a commercial solar cell. Topography characterisation Scanning electron microscopy measurements were performed using a FEI nanoSEM. Statistical analysis was done using the software imageJ.

\section{Conflicts of interest}

There are no conflicts to declare.

\section{Acknowledgements}

This work was supported by the Research Foundation Flanders (FWO) via postdoctoral fellowships (Christos Trompoukis, Jan Rongé and Jolien Dendooven) and FWO research project funding (Ji-Yu Feng) as well as the Flemish Government via longterm structural funding (Methusalem, Prof. Johan A. Martens and Prof. Roel Baets).

\section{Notes and references}

1 Greenpeace, "Energy [R]evolution" report 2015, https://www.greenpeace.org/canada/en/publication/1572/e nergy-revolution-2015-the-latest-documentation-2/

2 World Energy Council (2016) in collaboration with Accenture Strategy and Paul Scherrer Institute, World Energy Scenarios, https://www.worldenergy.org/publications/2016/worldenergy-scenarios-2016-the-grand-transition/

3 A. Fujishima, K. Honda, Nature, 1972, 238, 37.

4 T. Jesper Jacobsson, Energy Environ. Sci., 2018, 11, 1977.

5 M. Dumortier, S. Tembhurne, S. Haussener, Energy Environ. Sci., 2015, 8, 3614.

6 D. Bae, B. Seger, P. C. K. Vesborg, O. Hansen, I. Chorkendorff, Chem. Soc. Rev., 2017, 46, 1933.
7 C. Ros, T. Andreu, J. R. Morante, J. Mater. Chem. A, 2020, 8 10625-10669

8 W. Yang, R. R. Prabhakar, J. Tan, S. D. Tilley, J. Moon, Chem. Soc. Rev., 2019, 48, 4979-5015.

9 N. Y. Labrador, X. Li, Y. Liu, H. Tan, R. Wang, J. T. Koberstein, T. P. Moffat, D. V. Esposito, Nano Lett., 2016, 16, 6452.

10 S. Hu, N. S. Lewis, J. W. Ager, J. Yang, J. R. McKone, N. C. Strandwitz, J. Phys. Chem. C, 2015, 119, 24201.

11 J.W. Ager, M.R. Shaner, K.A. Walczak, I.D. Sharp, S. Ardo, Energy Environ. Sci., 2015, 8, 2811.

12 D. Bae, B. Seger, O. Hansen, P. C. K. Vesborg, I. Chorkendorff, ChemElectroChem, 2019, 6, 106.

13 X. Zhou, R. Liu, K. Sun, K. M. Papadantonakis, B. S. Brunschwing, N. L. Lewis, Energy Environ. Sci., 2016, 9, 892897.

14 C. Ros, T. Andreu, M. D. Hernandez-Alonso, G. Penelas-Perez, J. Arbiol, J. R. Morante, ACS Appl. Mater. Interfaces, 2017, 9, 17932-17941.

15 W. Shockley, H. Queisser, J Appl Phys., 1961, 32, 510.

16 K.T. Fountaine, H.J. Lewerenz, H.A. Atwater, Nat. Commun., 2016, 7, 13706 .

17 P. A. Nikolaychuk, Silicon, 2014, 6, 109

$18 \mathrm{~N}$. Takeno, Atlas of Eh-pH diagrams: Intercomposition of thermodynamics database, National Institute of Advanced Industrial Science and Technology, Tokyo, 2005.

19 D. V. Esposito, ACS Catal., 2018, 8, 457.

20 A. Standing, S. Assali, L. Gao, M. A. Verheijen, D. van Dam, Y. Cui, P. H. L. Notten, J. E. M. Haverkort, E. P. A. M. Bakkers, Nat. Commun., 2015, 6, 7824.

21 C. Trompoukis, A. Abass, J-W. Schuttauf, T. Bosserez J. Ronge, J. Lauwaert, J. A. Martens, R. Baets, Sol. Energy Mater. Sol. Cells, 2018, 182, 196.

22 F. Urbain, V. Smirnov, J.-P. Becker, A. Lambertz, F. Yang, J. Ziegler, B. Kaiser, W. Jaegermann, U. Ray, F. Finger, Energy Environ.Sci., 2016, 9, 145.

23 G. Agostinelli, A. Delabie, P. Vitanov, Z. Alexieva, H. F. W. Dekkers, S. De Wolf, G. Beaucarne, Sol. Energy Mater. Sol. Cells, 2006, 90, 3438

24 Md. A. Hossain, K. T. Khoo, X. Cui, G. K. Poduval, T. Zhang, X. Li, W. M. Li, B. Hoex, Nano Mater Sci, 2020, 2, 204-226

25 C. Trompoukis, O. El Daif, P.P. Sharma, H.S. Radhakrishnan, M. Debucquoy, V. Depauw, K. Van Nieuwenhuysen, I. Gordon, R. Mertens, J. Poortmans, Prog. Photovolt. Res. Appl., 2015, 23, 734

26 K. M. Gad, D. Vossing, A. Richter, B. Rayner, L. M. Reindl, S. E. Mohney,M. Kasemann, IEEE J Photovolt, 2016, 6, 649.

27 S. Duenas, H. Castan, H. García, E. San Andres, M. ToledanoLuque, I. Martil,G. Gonzalez-Díaz,K. Kukli,T. Uustare, J. Aarik, Semicond. Sci. Technol., 2005, 20, 1044-1051.

28 R. T. Pekarek, K. Kearney, B. M. Simon, E. Ertekin, A. A. Rockett, M. J. Rose, J. Am. Chem. Soc., 2018, 140, 1322313232.

29 Y. Lin, R. Kapadia, J. Yand, M. Zheng, K. Chen, M. Hettick, X. Yin, C. Battaglia, I. D. Sharp, J. W. Ager, A. Javey, J. Phys. Chem. C 2016, 119 (5), 2308-2313.

30 B. Seger, T. Pedersen, A. B. Laursen, P. C. K. Vesborg, O. Hansen, I. Chorkendorff, J. Am. Chem. Soc. 2013, 135, 1057-1064.

31 Z. Xing, F. Ren, H. Wu, L. Wu, X. Wang, J. Wang, D. Wan, G. Zhan, C. Jiang, Sci. Rep. 2017, 7, 43901.

32 M. J. Choi, J.-Y. Jung, M.-J. Park, J.-W. Song, J.-H. Lee and J. H. Bang, J. Mater. Chem. A 2014, 2, 2928.

33 T. Aaltonen, M. Ritala, T. Sajavaara, J. Keinonen, M. Leskelä, Chem. Mater. 2003, 15, 1924.

34 D. Longrie, K. Devloo-Casier, D. Deduytsche, S. Van den Berghe, K. Driesen, C. Detavernier, ECS J. Solid State Sci. Technol. 2012, 1, Q123.

35 J. Dendooven, R. K. Ramachandran, E. Solano, M. Kurttepeli, L. Geerts, G. Heremans, J. Ronge, M. M. Minjauw, T. Dobbelaere, K. Devloo-Casier, J. A. Martens, A. Vantomme, S. 
Bals, G. Portale, A. Coati, C. Detavernier, Nat. Commun. 2017, 8, 1074.

36 E. Kemppainen, A. Bodin, B. Sebok, T. Pedersen, B. Seger, B. Mei, D. Bae, P. C. K. Vesborg, J. Halme, O. Hansen, P. D. Lund, I. Chorkendorff, Energy Environ. Sci., 2015, 8, 2991-2999.

37 Y. Zhao, N. C. Anderson, K. Zhu, J. A. Aguiar, J. A. Seabold, J. van de Lagemaat, H. M. Branz, N. R. Neale, Nano Lett. 2015, 15,2517

38 J. Lu, B. Liu, N. P. Guisinger, P. C. Stair, J. P. Greeley, J. W. Elam, Chem. Mater., 2014, 26, 6752-6761.

39 R. K. Ramachandran, M. Filez, E. Solano, H. Poelman, M. M. Minjauw, M. Van Daele, J. Y. Feng, A. La Porta, T. Altantzis, E. Fonda, A. Coati, Y. Garreau, S. Bals, G. B. Marin, C. Detavernier, J. Dendooven, Chem. Mater., 2019, 31, 96739683.

40 K. Cao, L. Shi, M. Gong, J. Cai, X. Liu, S. Chu, Y. Lang, B. Shan, R. Chen, Small, 2017, 13, 1700648.

41 D. Arrington, M. Curry, S. Street, G. Pattanaik, G. Zangari, Electrochim. Acta, 2008, 53, 2644-2649.

42 J. Dendooven, E. Solano, M. M. Minjauw, K. Van de Kerckhove, A. Coati, E. Fonda, G. Portale, Y. Garreau, C. Detavernier, Review of Scientific Instruments, 2016, 87, 113905.

43 R. L. Puurunen, J Appl Phys, 2005, 97, 121301.

44 J. W. Elam; M. Schuisky; J. D. Ferguson, S. M. George, Thin Solid Films, 2003, 436, 145.

45 X. Qi, D. Deduytsche, M. Schaekers, M. Caymax, A. Delabie, X.P. Qu, C. Detavernier, Appl Phys Lett., 2010, 97, 112905. 